\title{
Antibiotics from Aspergillus amstelodami
}

\author{
By W. M. DARLING,* P. J. CAMPBELL AND MAURA McARDLE \\ Dept. of Microbiology, The Queen's University, Belfast, Northern Ireland
}

(Received 25 June 1962)

\section{SUMMARY}

\begin{abstract}
A strain of Aspergillus amstelodami, which antagonized the growth of Mycobacterium tuberculosis, was shown to produce at least two antibiotic substances. A liquid medium was developed for their production, and cultural and assay procedures were defined. The antibiotics appear to be distinct from previously described derivatives of the true fungi and were named Amodin A and Amodin B. Both are active against certain Grampositive and acid-fast organisms, but Amodin B has the wider antibiotic spectrum and is active against some Gram-negative organisms and strains of Candida albicans. Amodin A was produced in surface and submerged cultures, but in better yield in the latter; it was extracted and prepared as a crude product. It appears to be a moderately heat-labile peptide; though non-toxic to mice it did not prolong their survival when infected with Staphylococcus aureus or $M$. tuberculosis at the dosage of antibiotic used. Amodin B appeared only in surface cultures and was mainly present in the mycelium, from which it was liberated by dilute acid. It is relatively heatstable and not inactivated by proteolytic enzymes. Amodin A production appears to be linked with the conidial mode of sporulation and Amodin B with the perithecial mode.
\end{abstract}

\section{INTRODUCTION}

A strain of Aspergillus amstelodami appeared as a contaminant which inhibited the growth of Mycobacterium tuberculosis on a plate of Lowenstein-Jensen medium which had been exposed to ultraviolet radiation. The strain is characterized by the production of relatively few perithecia but abundant conidial heads and shows a physiological abnormality which affects its growth from light inocula (Darling \& McArdle, 1959). A culture (IMI 71295) has been deposited in the Commonwealth Mycological Institute, Ferry Lane, Kew, Surrey, England. The type of colonial variation may be of more than taxonomic interest because the different forms of sporulation may be associated with the formation of different antibiotics. We have found two antibiotics to be produced which we have named Amodin A and Amodin B.

\section{METHODS}

The fungus was maintained by mass inoculations of spores on Sabouraud medium or solid Czapek-Dox medium.

Production medium. Evans peptone (20 g.) and $\mathrm{NaCl}(5 \mathrm{~g}$.$) were dissolved in$ $900 \mathrm{ml}$. of distilled water, the solution was adjusted to $\mathrm{pH} 8 \cdot 4$, steamed for $\mathbf{1 ~ h r}$. and filtered. To this was added $40 \mathrm{~g}$. white table sugar, $7 \mathrm{ml}$. lactic acid (B.P.), 10 g. calcium lactate $\left(\mathrm{C}_{6} \mathrm{H}_{10} \mathrm{O}_{6} \mathrm{Ca} .5 \mathrm{H}_{2} \mathrm{O}\right)$ and $100 \mathrm{ml}$. Hartley's digest broth. The

* Present address-Mission Hospital, Sankeshwar, Belgaum District, Mysore State, India. 
solution was adjusted to $\mathrm{pH} 6.0$ with $\mathrm{N}-\mathrm{NaOH}$ and sterilized by autoclaving at $112^{\circ}$ for 30 min., during which the $\mathrm{pH}$ fell to $5 \cdot 0$.

Cultivation. Amodin A appeared in the metabolism solution of surface cultures, but was produced in greater quantities in submerged cultures in shaken flasks and on a larger scale in a deep fermentation unit. Shaken flask cultures were grown in $500 \mathrm{ml}$. Erlenmeyer flasks containing $125 \mathrm{ml}$. medium and three drops of lard oil to suppress foaming. The flasks were inoculated with about $10^{8}$ spores and shaken on a reciprocating shaker with $3 \frac{1}{2}$ in. stroke at 100 throws $/$ min. Incubation was at $30^{\circ}$ and the cultures were harvested on the 4 th day. Deep fermentation was carried out in an adapted Hoover washing machine (Nixon, Borrow \& Jefferys, 1959; details of technique will be supplied on request to the Department of Microbiology, The Queen's University, Belfast). Both methods gave similar results.

Amodin B was only produced in surface cultures. These were grown on layers of liquid medium about $4 \mathrm{~mm}$. in depth. Roux bottles containing $85 \mathrm{ml}$. medium were seeded with about $10^{7}$ spores/bottle from 4-day Sabouraud medium slope cultures. They were incubated at $32^{\circ}$ and harvested on the 6 th day. The metabolism solution was drained off and filtered through glass wool. The mycelium was then shaken with $30 \mathrm{ml} . \mathbf{0} \cdot 1 \mathrm{~N}-\mathrm{HCl}$ per bottle and the resulting acid solution similarly harvested. Solutions were stored at $4^{\circ}$ at $\mathrm{pH}$ 4-6.

In the cultivation of the fungus, formation of Amodin $\mathbf{A}$ appeared to be related to the occurrence of conidial sporulation and formation of Amodin $\mathbf{B}$ to the occurrence of perithecial. Thus in submerged cultures, where only conidial sporulation took place, Amodin A alone was detectable. In surface cultures, where both modes of sporulation occurred, the antibiotics appeared in phase with the phenomena of sporulation; conidial sporulation was beginning on the 2nd day and maximal on the 4th corresponding with the production of Amodin A, while perithecial sporulation was beginning on the 3rd or 4th day and maximal on the 6th corresponding with the production of Amodin B.

Extraction of Amodin $A$. Several methods of extraction were investigated, and the following was found to be the most satisfactory. Manipulations were carried out in a cold room $\left(4^{\circ}\right)$ and solutions and reagents were chilled before use. The filtered metabolism solution to be extracted was adjusted to $\mathrm{pH} \mathrm{5 \cdot 2-5 \cdot 6}$ with $0 \cdot 1 \mathrm{~N}-\mathrm{NaOH}$ and Norit charcoal (Savory \& Moore) was added (4 g./l.). After adsorption for $1 \mathrm{hr}$. the charcoal was recovered by filtration or centrifugation and washed with $0.05 \mathrm{~N}-\mathrm{HCl}$, resuspended in $0.01 \mathrm{~N}-\mathrm{HCl}$ and the suspension adjusted to $\mathrm{pH} 2 \cdot 1-$ 2.2. Acetone (4l. per l. suspension) was then added and the mixture shaken for $30 \mathrm{~min}$. The eluate was freed from charcoal by refrigerated centrifugation and the acetone removed by distillation under reduced pressure at temperatures near $40^{\circ}$. The concentrate was then shaken with twice its volume of diethyl ether and after separation the aqueous fraction was neutralized with $\mathrm{N}-\mathrm{NaOH}$. The ether layer was discarded and the residual ether in the aqueous fraction evaporated off under reduced pressure. The resultant clear yellow solution was freeze-dried.

Extraction of Amodin B. Metabolism fluid and the acid extract of the mycelium from surface cultures were concentrated by evaporation under reduced pressure, the temperature being kept below $75^{\circ}$. An unsuccessful search for a satisfactory extraction method was made. Charcoal adsorption with acetone elution and direct phenol extraction were tried. In the latter method enough phenol was used to 
saturate the solution and leave a layer of such volume that there was $1 \mathrm{ml}$. for each 100-200 units of activity to be extracted. Recovery of Amodin B from the phenol layer was effected by shaking with ten times its volume of diethyl ether to remove the phenol and then adding 1 volume of distilled water.

Assay of Amodin A. Corynebacterium fimi (NCTC 7547), very sensitive to Amodin A, was used for its assay. Suspensions were prepared from $48 \mathrm{hr}$. cultures on meat digest agar slopes, washed off with normal saline and adjusted to Brown's opacity tube No. 8. The assay technique, based on a method used for penicillin (Knudsen \& Randall, 1945), utilized the fact that with Amodin A, as with penicillin, the diameter of the zone of inhibition varies as the logarithm of the potency of the antibiotic, within the range of concentrations employed. Three replicate hole plates were used for each unknown. The medium consisted of Lab. Lemco, 1.5 g.; baker's yeast, 3.0 g.; Evans peptone, 6.0 g.; Davis agar, $15.0 \mathrm{~g}$., in 1 l. distilled water, and dissolved by boiling. The solution was adjusted to $\mathrm{pH} 7 \cdot 0$ and then autoclaved at $126^{\circ}$ for $20 \mathrm{~min}$. The plates $\left(4 \frac{1}{2} \mathrm{in}\right.$.) received first a $15 \mathrm{ml}$. base layer and then an $8 \mathrm{ml}$. flood layer of the same medium inoculated with C. fimi, $4 \mathrm{ml}$. suspension/ $100 \mathrm{ml}$. After hardening overnight at $4^{\circ}$, eight $9 \mathrm{~mm}$. diameter holes were punched in each. This provided one pair of holes for each of the four solutions used, i.e.: (1) lower concentration of standard; (2) lower concentration of unknown; (3) higher concentration of standard; (4) higher concentration of unknown (Fig. 1).

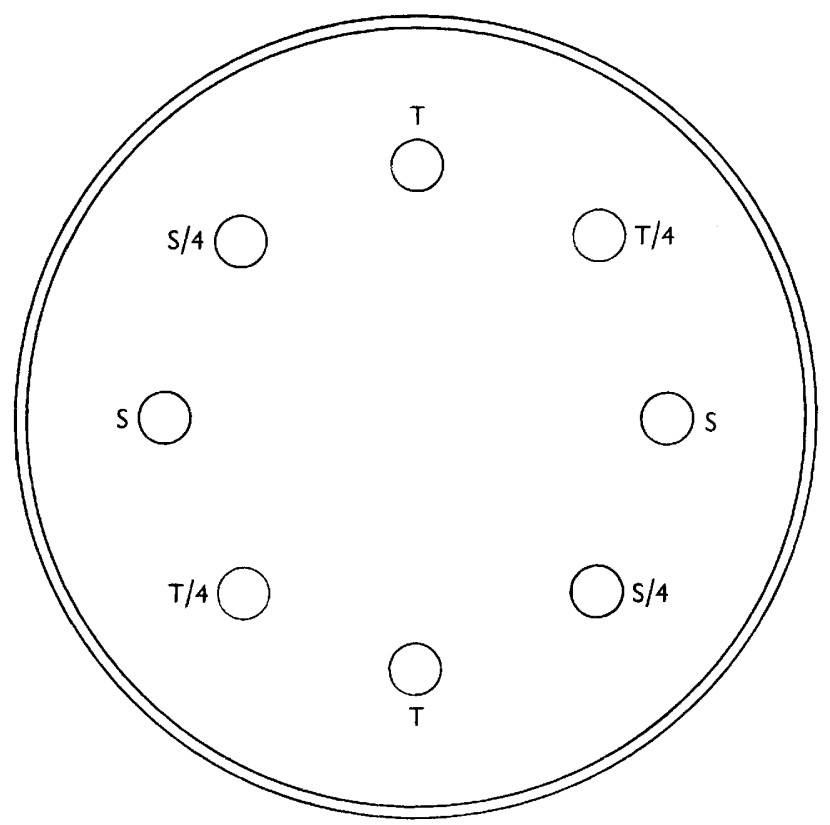

Fig. 1. Pattern of distribution of standard (S) and test (T) solutions on assay plates.

The dilution ratio (1/4), common to both the standard and unknown, was chosen in view of the gradual slope of the curve which relates the concentration of Amodin $\mathbf{A}$ with zone diameter. Potency of Amodin A preparations was referable to stable freezedried material having a potency of $100,000 \mathrm{units} / \mathrm{g}$. One unit in $1 \mathrm{ml}$. of nutrient 
agar was close to the minimal inhibitory concentration for Corynebacterium fimi. The standard solution was usually made to contain 100-200 units/ml., giving zones of inhibition about $25 \mathrm{~mm}$. in diameter. Statistical examination of results underlined the need for close approximation in potency of the unknown and standard. To obtain this a preliminary trial was sometimes necessary. The solutions were put into the holes using a pipette delivering a measured $0.1 \mathrm{ml}$. Zone diameters were measured after incubation at $32^{\circ}$ for $\mathbf{1 8 - 2 4} \mathrm{hr}$. Results were calculated according to standard statistical procedure for the evaluation of 4-point assays (Burn, Finney \& Goodwin, 1950). Often the same solution gave a'larger zone on one side of a plate than the other, due to inequality of agar depth. In the analysis of variance it was possible to eliminate a component from the sum of squares representing this potential source of error.

Assay of Amodin B. Mycobacterium smegmatis (NCTC 523) was sensitive to Amodin B and was used for its assay. Its use as a rapidly growing substitute for $M$. tuberculosis in the investigation of antituberculous substances was suggested by King, Knox \& Woodroffe (1953). For the preparation of assay plates $48 \mathrm{hr}$. digest broth cultures were grown at $37^{\circ}$. After these had been agitated to disperse the growth, time was allowed for the larger clumps to settle and then the supernatant fluid was pipetted off and the opacity adjusted to Brown's opacity tube No. 2. M. smegmatis was relatively insensitive to Amodin A. Technique was similar to that used for Amodin A, but with a dilution ratio of $1 / 2$ and nutrient agar as the medium and incubation at $37^{\circ}$ for $48 \mathrm{hr}$. The unit of activity for Amodin B was such that 1.5 units in $1 \mathrm{ml}$. of nutrient agar gave the minimal inhibitory concentration for $M$. smegmatis. A concentrate prepared by evaporation under reduced pressure of an acid extract of surface culture mycelium was used as standard material. This and other solutions were very stable and were stored for several months without appreciable loss of activity.

Antibacterial activity. This was tested using agar dilution plates in the case of all organisms except Mycobacterium tuberculosis. Plates containing fourfold dilutions of Amodin A from 1600 to 25 units/ml. were streaked with dilutions of overnight broth cultures of the test bacteria, except in the case of pneumococci and streptococci, which were inoculated directly from cultures on blood agar. Inhibition of $M$. tuberculosis strains was tested in Dubos Tween albumin liquid medium. A range of dilutions of the antibiotic was prepared in $3 \mathrm{ml}$. volumes of the medium in bijou bottles and one drop of a 5-day culture of $M$. tuberculosis was added to each. The antibacterial activity of Amodin B preparations was tested similarly.

\section{RESULTS WITH AMODIN A}

Assay results with Amodin A. An example of the type of results obtained in assays of Amodin A is presented in Table 1. In this experiment two samples (A and B, each 0.05 g.) of Amodin A freeze-dried material were dissolved in $10 \mathrm{ml}$. distilled water. The standard was a solution of Amodin A containing 280 units/ml. It may be noted that fiducial limits are much wider for the sample $B$ result (approx. $\pm \mathbf{2 8} \%$ of mean value) than for the sample $A$ (approx. $\pm 7 \%$ ). This is partly because the error sum of squares is greater in the case of the second group of plates, owing to uneven technique, and partly because there is a greater divergence of the sample solution potency from that of the standard. In general, with careful technique and 
good approximation of unknown and standard potencies, fiducial limits approaching $\pm 5 \%$ may be obtained.

Yield of Amodin $A$ in submerged cultures. Amodin A began to appear in the metabolism solution between the second and third day and reached a maximum on the fourth day of incubation; e.g. in one fermentation a maximum value of 120 units $/ \mathrm{ml}$. was reached at the end of 3 days; at this time the $\mathrm{pH}$ value of the culture, which had dropped to 4.2 at $32 \mathrm{hr}$., had risen again to $\mathrm{pH} 4.9$ and was still rising. The culture was harvested at $92 \mathrm{hr}$., by which time the $\mathrm{pH}$ was $5 \cdot 2$. The Amodin A concentration did not increase during the last $20 \mathrm{hr}$. of incubation, at least in the metabolism solution, but the delay gave time for the more complete utilization of nutrients, leaving less unwanted material in the harvested solution.

Table 1. Assay results from two samples of Amodin A freeze-dried material

(Sample A : Plates I-III. Sample B: Plates IV-VI.)

\begin{tabular}{|c|c|c|c|c|c|}
\hline \multirow[b]{2}{*}{ Plate } & \multicolumn{2}{|c|}{$\begin{array}{l}\text { Standard solutions, } \\
\text { zone diameters in } \mathrm{mm} \text {. }\end{array}$} & \multicolumn{2}{|c|}{$\begin{array}{c}\text { Sample solutions, } \\
\text { zone diameters in mm. }\end{array}$} & \multirow{2}{*}{$\begin{array}{l}\text { Relative potency } \\
\text { (fiducial limits) }\end{array}$} \\
\hline & Diluted $1 / 4$ & Undiluted & Diluted $\mathbf{1} / \mathbf{4}$ & Undiluted & \\
\hline I & $\begin{array}{l}22 \cdot 2 \\
21 \cdot 8\end{array}$ & $\begin{array}{l}27 \cdot 0 \\
27 \cdot 4\end{array}$ & $\begin{array}{l}23 \cdot 4 \\
23 \cdot 4\end{array}$ & $\begin{array}{l}28 \cdot 0 \\
28 \cdot 6\end{array}$ & \\
\hline II & $\begin{array}{l}22 \cdot 0 \\
21 \cdot 4\end{array}$ & $\begin{array}{l}27 \cdot 0 \\
26 \cdot 0\end{array}$ & $\begin{array}{l}22 \cdot 2 \\
23 \cdot 4\end{array}$ & $\begin{array}{l}28 \cdot 0 \\
27 \cdot 4\end{array}$ & $\begin{array}{c}1 \cdot 36 \\
(1 \cdot 25-1 \cdot 45)\end{array}$ \\
\hline III & $\begin{array}{l}18 \cdot 6 \\
19 \cdot 2\end{array}$ & $\begin{array}{l}24 \cdot 0 \\
25 \cdot 0\end{array}$ & $\begin{array}{l}20 \cdot 2 \\
20 \cdot 0\end{array}$ & $\begin{array}{l}25 \cdot 6 \\
24 \cdot 6\end{array}$ & \\
\hline IV & $\begin{array}{l}21 \cdot 0 \\
22 \cdot 0\end{array}$ & $\begin{array}{l}27 \cdot 2 \\
27 \cdot 0\end{array}$ & $\begin{array}{l}18 \cdot 0 \\
16 \cdot 8\end{array}$ & $\begin{array}{l}23 \cdot 2 \\
22 \cdot 8\end{array}$ & \\
\hline V & $\begin{array}{l}21 \cdot 6 \\
20 \cdot 4\end{array}$ & $\begin{array}{l}27 \cdot 6 \\
26 \cdot 6\end{array}$ & $\begin{array}{l}17 \cdot 6 \\
18 \cdot 2\end{array}$ & $\begin{array}{l}22 \cdot 2 \\
23 \cdot 2\end{array}$ & $\begin{array}{c}0 \cdot 36 \\
(0 \cdot 28-0 \cdot 48)\end{array}$ \\
\hline VI & $\begin{array}{l}22 \cdot 0 \\
20 \cdot 2\end{array}$ & $\begin{array}{l}27 \cdot 0 \\
26 \cdot 4\end{array}$ & $\begin{array}{l}16 \cdot 0 \\
16 \cdot 0\end{array}$ & $\begin{array}{l}21 \cdot 8 \\
23 \cdot 2\end{array}$ & \\
\hline
\end{tabular}

Results: sample A potency $=1 \cdot 36 \times 280 \times 200=76,160$ units $/ g$. (fiducial limits $=70,000-$ 81,200). Sample $B$ potency $=0.36 \times 280 \times 200=20,160$ units $/ g$. (fiducial limits $=15,680$ $26,880)$.

Extraction of Amodin A. The solubility of Amodin A in aqueous acetone falls off sharply with increase of the acetone concentration to the region of $80 \%$ by volume; this is the greatest concentration which can effectively be used for elution, but for routine purposes a lower concentration is preferable. In practice, the centrifuged deposit of washed charcoal at the beginning of the elution contains so much water that the addition of one volume of dilute acid and four volumes of acetone results in an effective concentration of about $76 \%(\mathrm{v} / \mathrm{v})$ acetone in water, which is satisfactory. There is advantage in adding the acid first because the charcoal readily suspends in it without aggregation, which occurs when the acetone is added first or ready-mixed with the acid. Also the $\mathrm{pH}$ value of the acid charcoal suspension is easy to test and to adjust to the value required. With this method, recovery of activity is virtually quantitative and a concentration of 10-20 times the potency in the starting fluid is achieved before freeze-drying. The figures for the last two extractions carried out on a 20 litre scale were 95 and $98 \%$ recovery of the starting activity. Column methods tried were inefficient, giving recoveries less than $40 \%$. 


\section{Physical properties of Amodin $A$}

Solubility. Amodin A is soluble in water, aqueous acetone, liquefied phenol, aqueous ethanol and methanol, slightly soluble in water-saturated $n$-butanol (300 units/ml.) and dry methanol (200 units/ml.) but insoluble in dry acetone, ethanol, $n$-butanol, ether, chloroform, ethyl acetate, amyl acetate.

Thermal stability. Metabolism solutions containing Amodin A lost activity at the rate of about 5-10\% monthly during storage at $4^{\circ}$. Concentrates stored in the cold at pH 2.0 were very stable and the monthly loss of activity was less than $2 \%$. Aqueous solutions were sufficiently stable at $\mathrm{pH} \mathrm{1 \cdot 0-8 \cdot 0}$ to undergo manipulation at room and incubator temperatures over periods of several hours without appreciable inactivation. Aqueous solutions at $\mathrm{pH} 3 \cdot 0-7 \cdot 0$ withstood immersion in boiling water for $6-8 \mathrm{~min}$; but over $90 \%$ inactivation occurred after exposure to free-flowing steam for $\mathbf{2 0}$ min. Losses of activity observed during extraction and solvent tests suggested that Amodin A is more sensitive to heat when dissolved in aqueous acetone and alcohols than when in aqueous solution.

Dialysis. Cellophane sacs (British Cellophane P'T 300) containing a solution of Amodin A (280 units $/ \mathrm{ml}$.) were suspended so as to rest on blocks of assay agar. After contact for $24 \mathrm{hr}$. the sacs were removed and the agar blocks and controls inoculated with Corynebacterium fimi. The results showed that Amodin A did not pass across the cellophan membranes. Solutions in such sacs did however lose activity, presumably by adsorption of the Amodin $A$ on the cellophan surface.

Paper strip chromatography of solutions containing Amodin A was carried out by the descending method with butanol plus acetic acid as solvent. After overnight development, the strips were dried and cut longitudinally. One side was cut into $1 \mathrm{~cm}$. pieces and placed on Corynebacterium fimi plates while the other was stained with Lissamine green. The Amodin A activity travelled as a broad colourless band having an $R_{F}$ value of $\mathbf{0 . 4 7}$. The chromatograms showed several distinct bands one of which corresponded in position with the biologically active one.

Paper strip electrophoresis was done by the horizontal open strip technique (Grassmann \& Hannig, 1952) using a potential of $120 \mathrm{~V}$., current of $2.5 \mu \mathrm{A}$., and buffers ranging from $\mathrm{pH} 8 \cdot 6$ to $\mathrm{pH} 2 \cdot 0$. Twenty-five $\mu$. of $20 \%$ or $30 \%(\mathrm{w} / \mathrm{v})$ solution of freeze-dried Amodin A active material was applied to the starting line and the current passed for $16 \mathrm{hr}$. The strips were then dealt with in the same way as those from chromatography. It was found that mobility of the Amodin A was greater at $\mathrm{pH} 8.6$ than at $\mathrm{pH} 7.5$ and much greater at $\mathrm{pH} 2$ than at $\mathrm{pH}$. The distribution of the biological activity on all strips was that of a single homogeneous substance which tended to spread out as a rather broad band.

Adsorption chromatography was done on columns of neutral alumina with aqueous butanol as solvent. After a short run the column was sucked dry, extruded and cut into $1 \mathrm{~cm}$. sections. Small amounts of these were plated on Corynebacterium fimi plates and the sections which showed antibiotic activity were eluted with 5 vol. acetone or methanol +2 vol. of $\mathrm{N} / 40 \mathrm{HCl}$, or were stained with Lissamine green. The biologically active fraction travelled down the column as a non-pigmented band which did not fluoresce in ultraviolet radiation. It travelled faster than the bands stained with Lissamine green and was separate from the lowest of these, though closely followed by it. 
Starch electrophoresis (Kunkel \& Slater, 1952; Stelos, 1956) showed that the antibiotically active fraction behaved as in paper strip electrophoresis at pH 2 . Continuous paper electrophoresis in a Grassmann apparatus as modified by Holdsworth (1955) showed that the antibiotic material moved satisfactorily on the paper, but appeared in the collecting tubes below the point of application without any lateral separation from inactive constituents. The potential used (160 V.) was obviously inadequate.

\section{Table 2. Results of three ultracentrifuge experiments}

Potencies of the top and bottom contents are expressed as percentages of
potency. Fiducial limits are shown in parentheses.
$\begin{array}{ccc}\text { Experiment } & \text { Top contents } & \text { Bottom contents } \\ \text { No. I (assay no. 84) } & 93 & 107 \\ \text { No. II (assay no. 86) } & (76-112) & (90-126) \\ & 89 & 112 \\ \text { No. III (assay no. 87) } & (81-96) & (101-120) \\ & (87-101) & (98-115) \\ \text { Means } & 94 & 108 \\ & (87-95) & (105-113)\end{array}$

Notes. In the case of assay no. 84 the wide fiducial limits are the result of lack of approximation in potency of the unknown and standard solutions. The fiducial limits for the means have been calculated on the basis of a combined variance estimate.

Ultracentrifugation. On three occasions solutions of about 1500 units/ml. potency, prepared from freeze-dried Amodin A material, were centrifuged in a Spinco preparative ultracentrifuge at $36,000 \mathrm{rev} . / \mathrm{min}$. for $1 \mathrm{hr}$. The top contents of the tubes were removed and assayed separately from the bottom and the washings of the emptied tubes were also tested. The results are shown in Table 2. In each case evidence of sedimentation was obtained, the bottom contents showing a concentration increase of the order of $10 \%$ and the top contents a corresponding decrease. In Expt. 2 the results were significant at the $\mathbf{0 . 9 5}$ probability level. When the results of the three experiments were combined a mean figure of $8 \%$ for the concentration change was obtained, with fiducial limits at $5 \%$ and $13 \%$. In none of the experiments did assay of the tube washings show evidence of deposition.

Absorption spectrophotometry. Samples of solutions resulting from adsorption chromatography were examined spectrophotometrically over the range of wavelengths from 210 to $320 \mathrm{~m} \mu$ but no absorption maxima correlating with the biological activity were found.

Effect of enzymes. Trypsin (Difco standard) in $0.25 \%(\mathrm{w} / \mathrm{v})$ concentration was incubated at $37^{\circ}$ with Amodin A (200 units $/ \mathrm{ml}$.) at pH $7 \cdot 1$ and 4.1. After $2 \mathrm{hr}$. no activity remained in the sample at $\mathrm{pH} 7 \cdot 1$ and after $2 \cdot 25 \mathrm{hr}$. at $\mathrm{pH} 4 \cdot 1$, less than $10 \%$. Papain (B.P.) at $0.5 \%(\mathrm{w} / \mathrm{v})$ produced a $70 \%$ inactivation in $2 \mathrm{hr}$. at $37^{\circ}$ at pH 4.6 and almost complete inactivation in $2.25 \mathrm{hr}$. at pH 6.3. Pepsin (B.P.) at $0.5 \%(\mathrm{w} / \mathrm{v})$ at $\mathrm{pH} 1.1$ showed a barely detectable effect after incubation at $37^{\circ}$ for $2 \mathrm{hr}$., whereas at $\mathrm{pH} 3 \cdot 8$ the activity was decreased by one-third in $2 \cdot 25 \mathrm{hr}$. With 


\section{W. M. Darling, P. J. Campbell and M. McArdie}

the same Pepsin and Amodin A concentrations, but incubation at $40^{\circ}$ for $24 \mathrm{hr}$., inactivation was complete at $\mathrm{pH} 4 \cdot 3$ but $25 \%$ of the control activity remained at $\mathrm{pH} 2 \cdot 2$.

Table 3. Antibacterial spectrum of Amodin $A$

Organisms (no. of strains in parentheses)

Concentrations
giving
partial
inhibition
(units/ml.)

Concentrations giving complete inhibition (units/ml)

Corynebacterium fimi (NCTC 7547) (assay test organism)

C. diphtheriae mitis (1)

C. diphtheriae gravis (1)

C. ulcerans (5)

Staphylococcus citreus (1)

$S$. aureus (Oxford strain)

S. aureus (2)

S. aureus (3)

S. aureus var. albus (1)

Sarcina lutea (1)

Streptococcus pyogenes (2)

S. viridans (3)

S. pneumoniae (5)

S. faecalis (7)

Bacillus anthracis (1)

B. subtilis (1)

B. megaterium (1)

Mycobacterium smegmatis (NCTC 523)

M. tuberculosis var. hom. (2)

M. tuberculosis var. bov. (1)

Mycobacterium sp. (NCTC 333)

Neisseria catarrhalis (1)

Bordetella bronchiseptica (1)

Haemophilus influenzae (1)

Escherichia coli (7)

Klebsiella pneumoniae (2)

Paracolon bacillus (1)

Proteus vulgaris (3)

P. vulgaris (1)

P. morgani (1)

Pseudomonas pyocyanea (4)

Salmonella typhi (1)

S. typhi (11)

S. paratyphi (1)

S. paratyphi (11)

S. typhimurium (3)

Salmonella sp. (7)

Shigella shigae (1)

Under 25

Under 25

$0 \cdot 8$

$1 \cdot 6$

Under 25

Under 25

100

400

100

10

25

100

25
100

400

Under 25

Under 25

Under 25

Under 25

100

400

1600

100

100

Under 25

Under 25

Under 25

Under 25

400

Over 1600

1600

400

400

30

60

30

4.00

60

1600

100

400

1600

100

400

Over 1600

Over 1600

Over 1600

400

400

1600

400

1600

400

1600

400

Over 1600

Over 1600

1600

400

S. flexneri (1)

$S$. sonnei (1)

Candida albicans (5)

Over 1600

1600

Over 400

Over 1600

Over 1600

1600

1600

Over 1600

1600

Over 1600

1600

Over 1600

Over 1600

Over 1600

1600

Over 1600

Over 1600

Over 400

In vitro antibacterial tests of Amodin $A$ preparations

Tests of the antibacterial activity of Amodin A preparations are summarized in Table 3. The antibiotic-containing plates were read soon after the growth on the control plates had reached its maximum. The plates contained only a limited range of concentrations serving to distinguish those organisms which were relatively 
sensitive from those which were relatively insensitive. As the units of measurement were arbitrarily chosen on the basis of biological effect, the results do not give any indication of the activity in terms of weight. The most active material prepared, still far from pure, had a specific activity of over 300,000 units/g. Amodin A preparations showed no antiviral activity when tested in tissue culture against type I poliovirus.

Development of resistance of staphylococci to Amodin A was studied with the Oxford strain and with a penicillin-resistant strain of pathogenic Staphylococcus aureus (M 381) isolated from a case of bovine mastitis and resistant to 10 units penicillin/ml. (Kindly supplied by Dr J. K. L. Pearson, Ministry of Agriculture, Stormont, Belfast.) Nutrient agar dilution plates were used and the organisms transferred several times by subculturing from the plate of highest concentration in the series which showed growth at each stage. Observations were made on the pattern of susceptibility to Amodin A in previously unexposed populations of staphylococci and on the emergence of resistant mutants during exposure. The results indicated that an inoculum of the order of $10^{6}$ cocci from an unexposed strain of staphylococcus was composed of individuals showing a very wide range of susceptibility to Amodin A and containing organisms capable of giving rise to substrains several times more resistant than the parent strain. The results also indicated that, while second-stage mutants of resistance 16 times the original were readily selected, mutation at higher degrees of resistance did not often occur. But this last conclusion is tentative because, using impure Amodin A-containing material to prepare the plates, it is not possible to be sure there was not some other factor than Amodin A making its presence felt at the higher concentrations.

\section{In vivo tests with Amodin $A$ preparations}

Toxicity. The acute intravenous toxicity of Amodin A was tested in mice with freeze-dried material containing 210,000 Corynebacterium fimi units/g. dissolved in distilled water to give $\mathbf{3} \%$ and $5 \%(\mathrm{w} / \mathrm{v})$ solutions. These were injected intravenously in amounts varying from 0.1 to $0.5 \mathrm{ml}$; only one dose was given. The mice were observed daily and weighed twice weekly. A few were sacrificed after 2 or 3 days, but the majority were observed for 4 weeks. Those sacrificed early were examined post mortem and liver, kidneys and spleen taken for histological examination. All 37 mice injected intravenously with a single dose of Amodin A solution survived. Of these, 5 received doses equivalent to more than $1 \mathrm{~g}$. dry material $/ \mathrm{kg}$. body weight. The largest dose was $0.5 \mathrm{ml}$. of a $5 \%$ solution containing 5250 units Amodin A; two mice of $15 \mathrm{~g}$. and one of $25 \mathrm{~g}$. received this and for the former it represented a dosage of $\mathbf{1} \cdot 67 \mathrm{~g}$. dry material $/ \mathrm{kg}$. body weight. These animals were distressed and collapsed after injection but recovery was quite rapid and appeared to be complete. On post-mortem examination no evidence of toxicity was found apart from some cast formation in the renal tubules which was thought to have arisen from haemolysis caused by the injected solution.

The chronic toxicity (subcutaneous injection) was assessed in the course of experiments to test the effect of Amodin A on experimental infections with Mycobacterium tuberculosis. A group of 7 uninfected treated mice increased in average weight from $17.5 \mathrm{~g}$. to $25 \mathrm{~g}$. in the 19 days of the test, while in the same period a group of five uninfected untreated controls increased from $15 \cdot 8$ to $20 \cdot 2 \mathrm{~g}$. The treated 
mice looked strong and physically normal with no sign of oedema; their appearance suggested that the injections had a favourable effect on growth.

Absorption and excretion. Urine from mice treated with Amodin A preparations was obtained at post-mortem examination and showed a concentration of between 100 and 200 units Amodin A/ml. urine; the blood concentration was about 10 units/ $\mathrm{ml}$. These findings suggest that Amodin A is absorbed from the subcutaneous tissues but is so freely excreted in the urine that a high blood concentration does not build up.

Mouse protection tests. The effect of Amodin A was tested in experimental infections with staphylococci and Mycobacterium tuberculosis in albino mice (strain VSBS) weighing 15-20 g.

Staphylococcus aureus strain PS/5 (kindly supplied by Professor E. T. C. Spooner, London School of Hygiene and Tropical Medicine) was used, which regularly produced multiple abscesses and death, usually within one week, after intravenous injection of $0 \cdot 1-0.2 \mathrm{ml}$. of broth culture. Groups of inoculated mice were treated as follows: Amodin A solution 3640 units $/ \mathrm{ml}$.: subcutaneous dosage $0.2 \mathrm{ml}$. or $0.5 \mathrm{ml}$. daily; Amodin A solution 7500 units/ml.; subcutaneous dosage $0.5 \mathrm{ml}$. daily or $0.5 \mathrm{ml}$. 3 times daily. The Amodin A solution was first injected within $1 \mathrm{hr}$. of inoculation. No prolongation of life resulted in mice given any of the above treatments as compared with controls.

For the tests with Mycobacterium tuberculosis the Ravenel strain (var. bovis) was used (Donovick, 1950). A dose of 0.2 ml. of a 5-day culture in Dubos Tween medium and containing $3.3 \times 10^{8} \mathrm{bacilli} / \mathrm{ml}$. was inoculated intravenously intolgroups of mice which were then treated as follows: groups injected with $6 \cdot 6 \times 10^{7}$ bacilli given Amodin A solution 2500 units $/ \mathrm{ml}$, $0.2 \mathrm{ml}$. daily, or $0.2 \mathrm{ml}$. twice daily; groups injected with $8 \times 10^{6}$ bacilli given Amodin A solution 5000 units $/ \mathrm{ml} ., 0.2 \mathrm{ml}$. daily or $\mathbf{0 . 2} \mathrm{ml}$. twice daily. No prolongation of life compared with the controls resulted from any of the treatments.

\section{RESULTS WITH AMODIN B}

Yield of Amodin B in surface cultures. Amodin B was detectable in the metabolism solution from the fourth day of incubation and reached a maximum on the sixth day but the concentration was never more than 5 or 6 units $/ \mathrm{ml}$. and often was only 1 or 2 units $/ \mathrm{ml}$. Extraction of the mycelium with diluted $\mathrm{HCl}$ gave a greater yield than the corresponding metabolism solution showed. The acid solution usually contained from 6 to 12 units $/ \mathrm{ml}$. and it had a much lower content of unwanted material than had the metabolism solution.

\section{Physical properties of Amodin $B$}

Solubility. This was similar to that of Amodin A except that the solubility of Amodin B in aqueous acetone solutions did not fall off sharply as the acetone concentration increased above $80 \%(\mathrm{w} / \mathrm{v})$ and concentrations of $85 \%$ and over could be used for elution.

Stability. Amodin B has greater stability than Amodin A and is more stable at $\mathrm{pH} 7.0$ than at $\mathrm{pH}$ 2. With aqueous solutions at $\mathrm{pH} 5$ to $\mathrm{pH} 7$ and at $4^{\circ}$ there was no detectable loss over periods of several months. When aqueous solutions at $\mathrm{pH} 7 \cdot 0$ 
or less were heated to $100^{\circ}$ for $15 \mathrm{~min} ., 5-10 \%$ inactivation occurred; at pH 9.0 under these conditions the degree of inactivation was greater. Aqueous solutions did not withstand open evaporation on a water bath but were readily concentrated by evaporation under reduced pressure at temperatures below $75^{\circ}$ at $\mathrm{pH}$ values between 5 and 7 . Inactivation took place when dry material was treated with anhydrous methanol and ethanol.

Effect of enzymes on Amodin B. The effect of $0 \cdot 125 \%(\mathrm{w} / \mathrm{v})$ trypsin at $\mathrm{pH} 7 \cdot 0$, papain $(0.5 \%, \mathrm{w} / \mathrm{v})$ at $\mathrm{pH} 6.8$ and pepsin $0.25 \%(\mathrm{w} / \mathrm{v})$ at $\mathrm{pH} 3.1$ were tested on a solution containing Amodin B 15 units $/ \mathrm{ml}$. The mixtures of antibiotic preparation +enzyme were incubated for $24 \mathrm{hr}$. at $37^{\circ}$. No decrease of antibiotic activity by any of these treatments was observed.

Dialysis. A method similar to that used for Amodin A was used. The test solution contained 20 units Amodin B/ml. and the cellophan sacs were left in contact with the agar blocks for 24 and for $72 \mathrm{hr}$. After 24 hr. the test organism (Mycobacterium smegmatis) showed partial inhibition and complete inhibition after $\mathbf{7 2} \mathrm{hr}$. contact, indicating a slow passage of Amodin B through the cellophan.

Antibacterial activity of Amodin B. Freeze-dried powder prepared directly from the acid extraction of surface culture mycelium was used; it contained 750 units Amodin B/g. and also a little Amodin A. In the dilutions used the Amodin A would not have been in sufficient concentration to affect the results. Plates containing 25 units, 5 units and 1 unit of Amodin B/ml. were prepared. The test procedure was similar to that used for Amodin A; the results are shown in Table 4. Amodin B showed no antiviral activity when tested in tissue culture against type I poliovirus.

\section{Examination of other strains of Aspergillus amstelodami for antibiotic effects}

Three strains of Aspergillus amstelodami from the Commonwealth Mycological Institute (CMI) all gave evidence of antibiotic production; comparisons with our strain showed well marked differences however (Table 5). On solid media none of the CMI strains produced zones inhibitory to Corynebacterium fimi, which suggests that they produce little if any Amodin A. On liquid media the two CMI strains examined produced greater inhibitory activity on Mycobacterium smegmatis than did our strain, but it is not certain whether this was due to Amodin B or notunlike the result with our strain the activity present in the metabolism solutions of the CMI strains was greater than that in eth acid extracts of mycelium. With the third test organism, a strain of Bacillus, the three CMI strains produced inhibitory zones on solid media but our strain did not, indicating that they produced some other antibacterial substance distinct from Amodin A and Amodin B.

\section{DISCUSSION}

The genus Aspergillus contains many antibiotic-producing species. All of the fourteen groups into which the genus has been classified (Thom \& Raper, 1945) include one or more antibiotic-producing species (Brian, 1951). In the large Aspergillus glaucus group, nine species have previously been shown to produce antibacterial substances (Wilkins \& Harris, 1942, 1945; Gill-Carey, 1949; Furtado, 1944; Gupta \& Viswanathan, 1955) and $A$. amstelodami can be added as a further example. Gill-Carey (1949) examined a strain of $A$. amstelodami and did not observe 
Table 4. Antibacterial spectrum of Amodin B

Organisms (no. of strains in parentheses)

Corynebacterium diphtheriae mitis (1)

C. diphtheriae gravis (1)

C. ulcerans (5)

C. fimi (NCTC 7457)

Staphylococcus aureus (7)*

S. citreus (1)

Sarcina lutea (1)

Streptococcus pyogenes (1)

S. pyogenes (1)

S. viridans (3)

S. pneumoniae (1)

S. pneumoniae (4)

$S$. faecalis (7)

Bacillus anthracis (1)

B. subtilis (1)

B. megaterium (1)

Mycobacterium tuberculosis var. hom. (1)

$M$. smegmatis (NCTC 523) (assay test organism)

Mycobacterium sp. (NCTC 333)

Neisseria catarrhalis (1)

Bordetella bronchiseptica (1)

Haemophilus influenzae (1)

Escherichia coli (3)

E. coli (4)

Klebsiella pneumoniae 9 (2)

Paracolon bacillus (1)

Proteus vulgaris (4) and morgani (1)

Pseudomonas pyocyanea (4)

Salmonella typhi (11)

S. paratyphi (1)

$S$. paratyphi $(\mathbf{1})$

S. typhimurium (3)

Salmonella sp. (3)

Salmonella sp. (4)

Shigella shigae (1) flexneri (1) and sonnei (1)

Candida albicans (5) (on Todd \& Hewitt agar) (on Sabaraud agar)

Saccharomyces sp. (1) (on Todd \& Hewitt agar) (on Sabaraud agar)

$\begin{array}{cc}\text { Concentrations } & \begin{array}{c}\text { Concentrations } \\ \text { giving }\end{array} \\ \text { giving } \\ \text { partial } & \text { complete } \\ \text { inhibition } & \text { inhibition } \\ \text { (units } / \mathrm{ml} \text { ) } & \text { (units } / \mathrm{ml} \text {.) }\end{array}$

\begin{tabular}{rr}
1 & 5 \\
Under 1 & Under 1 \\
1 & 5 \\
1 & 5 \\
1 & 5 \\
1 & 5 \\
Over 1 & 5 \\
Over 5 & 5 \\
Over 5 & 5 \\
Over 1 & 25 \\
Over 5 & 25 \\
Over 5 & 5 \\
Over 1 & 25 \\
5 & 25 \\
Under 1 & 5 \\
\hline
\end{tabular}

Under 1

Under 1

$\mathbf{5}$

Over 25

Over 5

Over 25 Over 25

Over $25 \quad$ Over 25

Over 25

Over 25

Over 25

Over 5

25

Over 25

$\begin{array}{rr}25 & \text { Over } 25 \\ 5 & 25 \\ 25 & 25\end{array}$

Over $25 \quad$ Over 25

$\begin{array}{rr}1 & 5 \\ 8 & 16 \\ \text { Under } 1 & \text { Under } 1\end{array}$

$1 \quad 5$

* Including 'aureus', 'albus', Oxford and penicillin-resistant strains.

antibiotic activity, but this may illustrate the general principle that antibioticproduction is a strain, rather than a species, characteristic (Wilkins \& Harris, 1945). Even when strains possess the capacity to produce antibiotics, the detection of this property depends to a considerable degree on successful selection of suitable growth conditions and test organisms. It is possible that antibiotic-production will prove a common finding among $\boldsymbol{A}$. amstelodami strains.

The question arises whether Amodin A and Amodin B are identifiable with any previously characterized antibiotics. As far as can be seen, it would appear unlikely. Most antibiotics obtained from the true fungi have been extractable by such solvents 
Table 5. Comparison of strains for antibacterial effects

$\begin{array}{cccc}\text { Strain } & \begin{array}{c}\text { Effect on } \\ \text { Corynebacterium } \\ \text { fimi }\end{array} & \begin{array}{c}\text { On } \\ \text { Mycobacterium } \\ \text { smegmatis } \\ \text { (solid medium) }\end{array} & \begin{array}{c}\text { On } \\ \text { (liquid medium) } \\ \text { bacillus } \\ \text { (solid medium) }\end{array} \\ \text { Our strain } & ++ & + & - \\ \text { IMI 57394 } & -- & ++ & ++ \\ \text { IMI 17455 } & -- & ++ & + \\ \text { IMI 16110 } & -- & \text { Not examined } & \pm\end{array}$

as chloroform and ether, and, of the few which are not, none corresponds in all its properties with either of the substances studied here.

Though pure samples of Amodin A and Amodin B have not been obtained it is possible to draw some conclusions about their chemical nature. In the case of Amodin A, its failure to dialyse, its relatively slow diffusion in agar and its behaviour in the ultracentrifuge indicate a fairly large molecule, and that this has a polypeptide structure is indicated by the inactivating effect of proteolytic enzymes. In the case of Amodin B, its dialysability and its relatively rapid diffusion in agar and its resistance to inactivation by proteolytic enzymes indicate a smaller molecule of a different character.

Regarding therapeutic potentialities, the mouse-protection tests carried out with Amodin A gave no indication of therapeutic activity at the level of dosage employed, but neither was there evidence of toxicity; in fact, uninfected mice receiving injections of Amodin A showed a greater weight gain and stronger physique than controls. The subject requires further study.

We wish to thank Dr N. G. Heatley, Oxford, for his interest and advice throughout this investigation, the Commonwealth Mycological Institute, Kew, for identification of the fungus and for the supply of other cultures for comparison, Dr K. B. Raper, Wisconsin, for a helpful discussion of the peculiarities of this strain and Dr J. E. Mackinnon for similar advice. We also wish to acknowledge gratefully the gift of a washing machine by Messrs Hoover and the ideas and information as to its adaptation as a fermenter passed on by Mr I. S. Nixon, Akers Research Laboratories, I.C.I. We also thank Dr Gladys Seymour for assistance at the time of testing surface culture, Mr H. Cox for technical help in the development of the special media used, and Mr F. Burns and other members of the technical staff here for much assistance. Finally we acknowledge very gratefully the encouragements and counsel of Dr N. C. Graham, head of this department at the beginning of the work, and Professor G. W. A. Dick during the later stages, who has also given criticism and advice and has assisted in the preparation of this paper. Dr Darling was in receipt of a grant from the Northern Ireland Hospitals Authority during the later stages of the work, Dr Campbell and Miss McArdle were in receipt of grants from the Medical Research Council. We wish to gratefully acknowledge these grants. 


\section{REFERENCES}

Brian, P. W. (1951). Antibiotics produced by fungi. Bot. Rev. 17, 357.

Burn, J. H., Finney, D. J. \& Goodwin, L. G. (1950). Biological Standardization. Oxford University Press.

Darling, W. M. \& MCARDLe, M. (1959). Effect of inoculum dilution on spore germination and growth in a mutant strain of Aspergillus amstelodami. Trans. Brit. mycol. Soc. 42, 235.

Donovick, R. (1950). The use of the mouse in the experimental investigation of tuberculosis. Ann. N.Y. Acad. Sci. 52, 671.

Furtado, A. R. (1944). Pesquisa da atividade antibacteriana com. 180 amostras de Aspergillus Micheli. Mem. Inst. Oswe. Cruz. 41, 205.

Gill-Carey, D. (1949). Antibiotics from Aspergilli. Brit. J. exp. Path. 30, 114.

Grassmann, W. \& Hannig, K. (1952). Ein quantitatives Verfahren zur Analyse der Serumproteine durch Papier-Elektrophorese. Z. physiol. Chem. 290, 1.

Gupta, K. C. \& Viswanathan, R. (1955). Antituberculous substances from Aspergillus proliferans and $A$. variecolor. Antibiot. Chemother. 5, 496.

Holdsworth, E. S. (1955). An apparatus for continuous electrophoresis on paper. Biochem. J. 59, 340.

King, M. B., KNox, R. \& Woodroffe, R. C. (1953). Investigation of antituberculous substances-an agar diffusion method using Mycobacterium smegmatis. Lancet, i, 573.

Knudsen, L. F. \& Randall, W. A. (1945). Penicillin assay and its control chart analysis. J. Bact. 50, 187.

Kunkel, H. G. \& Slater, R. J. (1952). Zone electrophoresis in a starch supporting medium. Proc. Soc. exp. Biol., N.Y. 80, 42.

Nixon, I. S., Borrow, A. \& JefFerys, E. G. (1959). Washing machines as laboratory fermenters. Brit. chem. Engng, May 1959.

Stelos, P. (1956). Electrophoretic and ultracentrifugal studies of rabbit hemolysins. J. Immunol. 77, 396.

Thом, C. \& RAPer, K. B. (1945). A Manual of the Aspergilli. Baltimore: Williams and Wilkins.

Wilkins, W. H. \& Harris, G. C. M. (1942). Investigation into the production of bacteriostatic substances by fungi. I. Preliminary examination of 100 fungal species. Brit. $J$. exp. Path. 23, 166.

Wilkins, W. H. \& Harris, G. C. M. (1945). Investigation into the production of bacteriostatic substances by fungi. V. Preliminary examination of the third 100 fungi with special reference to strain variation among species of Aspergillus. Trans. Brit. mycol. Soc. 27, 113. 